\title{
PATTERN RECOGNITION IN GAMMA-GAMMA COINCIDENCE DATA SETS
}

\author{
D.R. Manatt \\ F.L. Barnes \\ J.A. Becker \\ J.V. Candy \\ E.A. Henry \\ M.J. Brinkman
}

This paper was prepared for the Seventh International Symposium on Capture Gamma-Ray Spectroscopy and Related Topics

Pacific Grove, CA

October 14-19, 1990

October 1990

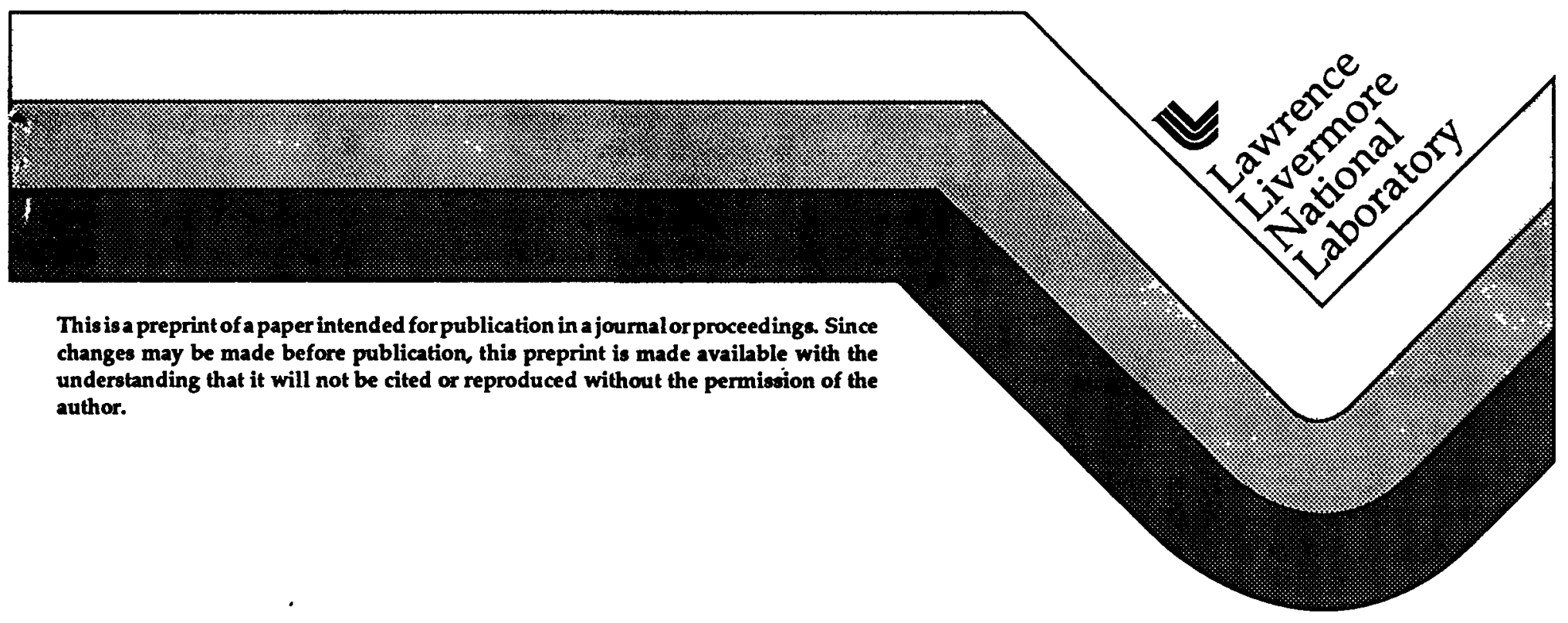




\section{DISCLAIMER}

This report was prepared as an account of work sponsored by an agency of the United States Government. Neither the United States Government nor any agency Thereof, nor any of their employees, makes any warranty, express or implied, or assumes any legal liability or responsibility for the accuracy, completeness, or usefulness of any information, apparatus, product, or process disclosed, or represents that its use would not infringe privately owned rights. Reference herein to any specific commercial product, process, or service by trade name, trademark, manufacturer, or otherwise does not necessarily constitute or imply its endorsement, recommendation, or favoring by the United States Government or any agency thereof. The views and opinions of authors expressed herein do not necessarily state or reflect those of the United States Government or any agency thereof. 


\section{DISCLAIMER}

Portions of this document may be illegible in electronic image products. Images are produced from the best available original document. 
PATTERN RECOGNITION IN GAMMA-GAMMA COINCIDENCE DATA SETS

\author{
D. R. Manatt, F. I. Barnes, J. A. Becker \\ J. V. Candy, E. A. Henry \\ Lawrence Livermore National Laboratory \\ Livermore, CA 94550, USA
}

M. J. Brinkman

Rutgers University

New Brunswick, NJ 08903, USA

\begin{abstract}
Considerable amounts of tedious labor are required to manually scan high-resolution ID slices of two dimensional $\gamma-\gamma$ coincident matrices for relevant and exciting structures. This is particularly true when the interesting structures are of weak intensity. We are working on automated search methods for the detection of rotational band structures in the full $2 \mathrm{D}$ space using pattern recognition techniques. For nominal sized data sets (1024x1024), however, these techniques only become computationally feasible through the use of Fourier Transform methods. Furthermore the presentation of data matrices as images rather than series of ID spectra has been shown to be useful. In this paper we will present the data manipulation techniques we have developed.
\end{abstract}

\title{
INTRODOCTION
}

By examining a two-dimensional data set as a multidimensional entity, features that are obscured by interfering lines in the one-dimensional gated slices can be characterized. Fast fourier transform methods allow the use of generalized correlation techniques to detect and characterize patterns in the full two-dimensional space.

We use these correlation techniques to search a $\gamma-\gamma$ coincident matrix for a fixed pattern of gaussian peaks in two dimensions, which is representative of the decay of a high spin rotational band. These methods extend our detection capability to include groups of very low intensity peaks. 
The correlation technique provides only the probable location of the centroid of patterns matching a given mask pattern in our data set, but with the proper choice of mask pattern, additional visually useful clues can be extracted. If the mask is chosen to have about half the extent of the pattern in the data set, multiple centroids will be indicated. If, in addition, the mask is configured with a fixed spacing and an odd number of rows and columns, the centroid of the mask corresponds to a point that falls on the middle row and middle column of the mask pattern, thus the indicated centroids will lie on many of the corresponding peaks in the data set.

\section{ROTATIONAI BANDS}

The correlation mask is determined by the pattern that one is searching for, in this case the gamma energies characteristic of high spin rotational bands. These energies are given by:

$$
E_{\gamma}=\frac{h^{2}}{2 J}(4 I-2)
$$

Thus theory tells us that the band members are evenly spaced. Furthermore, in a $\gamma \gamma$ coincidence matrix the peaks will be found in a square matrix with the diagonal absent. Figure 1 shows a typical $5 \times 5$ correlation mask with a spacing of $40 \mathrm{kev}$, which is characteristic of the rotational structures of interest.

\section{ANALYSIS METHOD}

To perform this analysis we first compress the data matrix by by a factor of four and apply an uncorrelated background removal! A correlation mask is then built with the expected gamma-ray energy spacing. The cross correlation of the mask and the $\gamma \gamma$ coincidence matrix is calculated and the correlation spectrum is examined for peaks indicating a pattern match. The peaks thus detected 


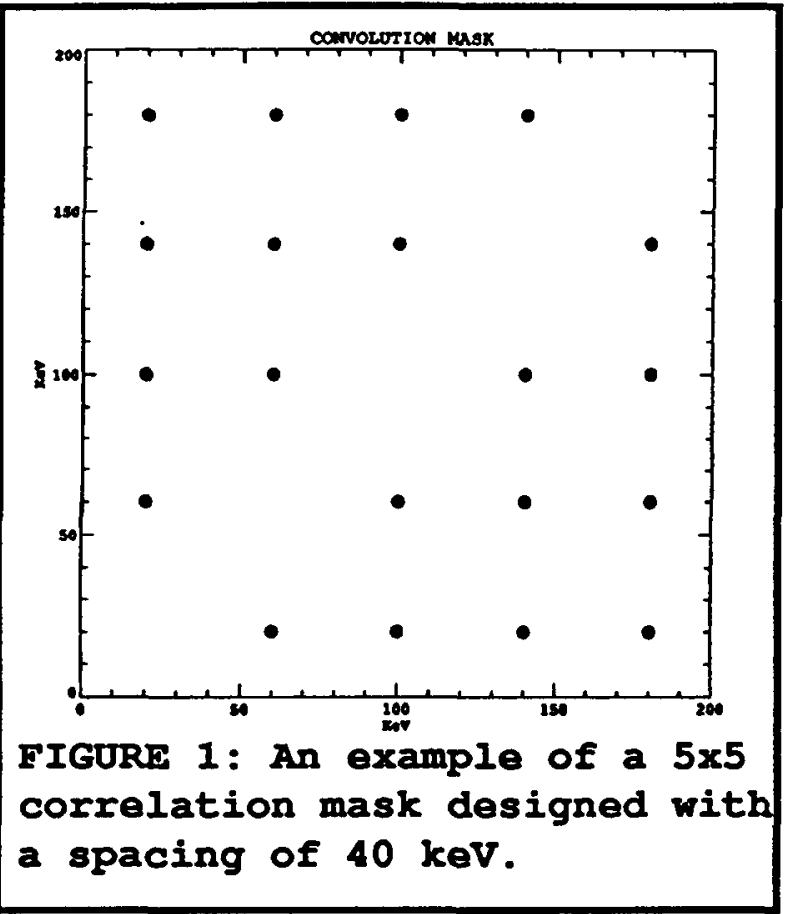

are then characterized in the background subtracted data matrix.

To increase the sensitivity of the correlation process, additional transformation can be performed on the data matrix. The most common examples are upper limit thresholding to reduce the contribution of large ground state peaks to the correlation spectrum, and lower limit thresholding to eliminate artifacts resulting from the background removal process.

\section{SUMMARY}

Our preliminary results with this method indicate that the use of two-dimensional correlation techniques increases our ability to detect and characterize weak rotational band structures. We are continuing to develop this and other multi-dimensional analysis methods to characterize the shapes and the intensities of rotational band transitions.

* Hork performed under the auspices of the U.S. Department of Energy by the Lawrence Iivermore National Laboratory

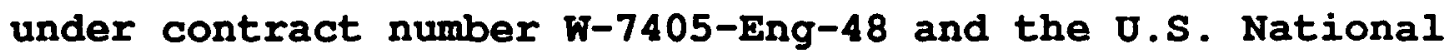
Science Foundation (Rutgers).

10 . Andersen et al., Phys. Rev. Let. 43687 (1979) 